\title{
A INTERPRETAÇÃO DA GRATUIDADE DO ENSINO À LUZ DA VEDA- ÇÃO DA PROTEÇÃO DEFICIENTE: A COBRANÇA DE MENSALIDA- DES EM UNIVERSIDADES PÚBLICAS
}

\author{
Mario Vinicius Rosario Wu* \\ Erivaldo Cavalcanti e Silva Filho**
}

SUMÁRIO: Introdução; 2 A Educação na Constituição de 1988; 3 AJurisprudência do Supremo Tribunal Federal; 4 A Decisão do STF no RE no 597.854/GO; 5 O Princípio da Proteção Não Deficiente; 6 Considerações Finais; Referências.

RESUMO: A atual realidade das universidades públicas brasileiras é a escassez. O objetivo da pesquisa foi verificar a necessidade de se reinterpretar a garantia da gratuidade do ensino público nos estabelecimentos oficiais de ensino superior. Concluiu-se que o princípio da vedação da proteção deficiente determina essa reinterpretação, pois há valores e objetivos constitucionais que estão sendo protegidos de maneira não razoável, através de uma interpretação desproporcional que universaliza essa gratuidade, ignorando a dimensão objetiva dos direitos fundamentais. Os resultados evidenciaram que cobranças de mensalidades em Universidades Públicas, inclusive na graduação, não ferem a Constituição, mas, ao contrário, viabilizam promoção de valores e objetivos tutelados por ela. A metodologia utilizada foi a pesquisa qualitativa, consistente em identificar e interpretar as informações necessárias sobre o assunto e estabelecer descritivamente os fenômenos a fim de promover análise do objeto, bem como a pesquisa bibliográfica, com uso de doutrina, legislação e jurisprudência.

PALAVRAS-CHAVE: Gratuidade do Ensino; Hermenêutica constitucional; Proporcionalidade; Vedação da proteção deficiente.

\section{THE INTERPRETATION OF FREE TUITION IN THE LIGHT OF IMPAIRMENT FROM DEFICIENT PROTECTION: FEES IN PUBLIC UNIVERSITIES}

ABSTRACT: Scarcity is the hallmark of Brazilian public universities. Current research analyzes the need of reinterpreting free tuition in government-run universities. The

\footnotetext{
Mestrando do Programa de Pós-Graduação em Direito Ambiental da Universidade do Estado do Amazonas. Oficial de Justiça do Tribunal Regional do Trabalho da $11^{\mathrm{a}}$ Região, Brasil.

E-mail:wu_mario@hotmail.com

* Doutor em Desenvolvimento Sustentável e Mestre em Ciência Política. Atualmente é Coordenador do Programa de Mestrado em Direito Ambiental (PPGDA) da Universidade do Estado do Amazonas (UEA), Brasil.
} 
principle of impairment from deficient protection determines the reinterpretation. In fact, several constitutional values and objectives that are protected unreasonably through a non-proportional interpretation that extends free tuition to all and discards the objective dimension of basic rights. Results reveal that the paying of tuition in public universities, including undergraduate courses, does not go against the Brazilian Constitution. On the contrary, it enhances values and aims protected by it. Current qualitative research identifies and interprets the necessary information on the subject and establishes the phenomenon to promote the analysis of the theme, bibliography, doctrine, legislation and jurisprudence.

KEY WORDS: Constitutional interpretation; Free tuition; Proportionality; Forbidding deficient protection.

\section{LA INTERPRETACIÓN DE LA GRATUIDAD DE LA ENSEÑANZA A LA LUZ DEL CIERRE DE LA PROTECCIÓN DEFICIENTE: LA COBRAN- ZA DE MENSUALIDADES EN UNIVERSIDADES PÚBLICAS}

RESUMEN: La actual realidad de las universidades públicas brasileñas es la escasez. El objetivo de la investigación fue verificar la necesidad de reinterpretarse la garantía de la gratuidad de la enseñanza pública en los establecimientos oficiales de enseñanza universitaria. Se concluye que el principio del cierre de la protección deficiente determina esa reinterpretación, pues hay valores y objetivos constitucionales que están protegidos de manera no razonable, por intermedio de una interpretación desproporcional que universaliza esa gratuidad, ignorando la dimensión objetiva de los derechos fundamentales. Los resultados evidenciaron que cobranzas de mensualidades en Universidades Públicas, incluso en la graduación, no lesionan la Constitución, sino, al contrario, viabilizan promoción de valores y objetivos tutelados por ella. La metodología utilizada fue la investigación cualitativa, consistente en identificar e interpretar las informaciones necesarias sobre el asunto y establecer descriptivamente los fenómenos a fin de promover análisis del objeto, así como la investigación bibliográfica, con uso de doctrina, legislación y jurisprudencia.

PALABRAS CLAVE: Hermenéutica Constitucional; Gratuidad de la Enseñanza; Proporcionalidad; Cierre de la Protección Deficiente. 


\section{INTRODUÇÃO}

O Supremo Tribunal Federal (STF) reconheceu a possibilidade de as universidades públicas cobrarem por cursos de especialização. Por maioria de votos, os ministros deram provimento ao Recurso Extraordinário (RE) 597.854-GO ${ }^{03}$.

Prevaleceu no plenário do STF a tese de que a garantia de gratuidade de ensino público prevista no art. 206, inciso IV, da Constituição da República Federativa do Brasil (CRFB), não obsta a cobrança por universidades públicas de mensalidades em cursos de especialização. O STF não decidiu sobre cobranças em cursos de graduação e de pós-graduação stricto sensu.

Feita essa contextualização do assunto, identificamos o seguinte problema, que será trabalhado nesta pesquisa: o STF foi muito aquém do que deveria, ao se limitar a permitir a cobrança nos cursos de pós-graduação lato sensu tão somente. Uma correta interpretação das normas constitucionais que dizem respeito à educação não pode promover o agravamento do quadro atual de sucateamento e escassez das instituições públicas de ensino superior.

O objetivo geral desta pesquisa é analisar a delimitação do alcance do princípio da gratuidade do ensino público em estabelecimentos oficiais, em todos os cursos de nível superior, à luz do princípio da vedação da proteção deficiente. $\mathrm{O} o b$ jetivo específico é examinar se, nesses estabelecimentos, cobranças de valores para se cursar a graduação e a pós-graduação stricto sensu ferem a Constituição de 1988.

A justificativa da pesquisa reside no atual cenário dos estabelecimentos oficiais de ensino público gratuito de nível superior, em que falta dinheiro para o básico, como conservação e limpeza. Assim, verificaremos se o princípio da proporcionalidade está sendo observado, ao se permitir que aqueles que podem pagar se beneficiem gratuitamente dos serviços educacionais ofertados pelos estabelecimentos oficiais de ensino superior. Pretendemos averiguar se a garantia de gratuidade do ensino nesses estabelecimentos está sendo interpretada de acordo com os valores e objetivos da Constituição, mormente o da melhoria da qualidade do ensino, o da ampliação do acesso ao nível superior e o da isonomia, bem como se a melhor exegese é a que garante essa gratuidade apenas àqueles que comprovem dela necessitar,

\footnotetext{
${ }^{03}$ BRASIL. Recurso Extraordinário número 597.854-GO. Universidade Federal de Goiás e Tiago Macedo dos Santos. Relator Ministro Edson Fachin. 28 de abril de 2017. In: Diário da Justiça Eletrônico (Brasília). Disponível em: < http://redir.stf.jus.br/paginadorpub/paginador.jsp?docTP=TP\&doclD=13642927> Acesso em: 09 jul. 2018.
} 
em todos os cursos de nível superior oferecidos pelas universidades públicas.

A metodologia utilizada foi a pesquisa qualitativa que consiste em identificar e interpretar as informações necessárias sobre o assunto investigado e estabelecer descritivamente os fenômenos a fim de promover uma análise do seu objeto. Nesta pesquisa iremos abordar a gratuidade em cursos de nível superior. Não é nosso intuito falar da gratuidade em outros níveis de ensino.

Para tanto, na primeira seção abordaremos o tratamento dado à educação pela Constituição de 1988, com o auxílio de autores que discutem esse tema. Na segunda seção, será feita uma análise jurisprudencial: verificaremos alguns precedentes do STF nos quais houve discussão acerca de algumas cobranças feitas por estabelecimentos oficiais de ensino público. Na terceira seção, a pesquisa continuará a analisar jurisprudência, porém, examinaremos especificamente a decisão do STF no RE $\mathrm{n}^{0} 597.854 / \mathrm{GO}$, em que se decidiu pela possibilidade das universidades públicas cobrarem por cursos de especialização. Por fim, discutiremos, na quarta seção, a aplicação do princípio da proteção não deficiente à interpretação da garantia da gratuidade do ensino público em estabelecimentos oficiais, com o subsídio da doutrina.

\section{A EDUCAÇÃO NA CONSTITUUIÇÃO DE 1988}

A Constituição de 1988 expressamente reconhece a educação como um direito fundamental de natureza social, em especial, no seu art. $6^{\circ}$, que inaugura o Capítulo II (dos direitos sociais) do Título II (dos direitos e garantias fundamentais).

Duarte $^{04}$ esclarece que o direito à educação se concretiza com a efetivação de prestações positivas por parte do poder público:

O Estado deve aparelhar-se para fornecer a todos, progressivamente, os serviços educacionais mínimos. Isso significa reconhecer que o direito à educação só se efetiva mediante o planejamento e a implementação de políticas públicas. Em outras palavras, a satisfação do direito não se esgota na realização do seu aspecto meramente individual (garantia de uma vaga na escola, por exemplo), mas abrange a realização de prestações positivas de natureza diversa por parte do poder público, num processo que se sucede no tempo.

${ }^{04}$ DUARTE, Clarice Seixas. A educação como um direito fundamental de natureza social. Educação \& Sociedade, Campinas, v. 28, n. 100 - Especial, p. 691-713, out. 2007, p. 710. 
O art. 193 inaugura o Título VIII (da ordem social) com a seguinte disposição geral: "a ordem social tem como base o primado do trabalho, e como objetivo o bem-estar e a justiça sociais". Se o objetivo de toda a ordem social é o bem-estar e a justiça sociais, esse também deve ser o objetivo da educação. Na parte final do art. 205, a Lei Maior especifica o conteúdo do bem-estar e da justiça sociais promovidos pela educação, ao estabelecer que o objetivo da educação é o pleno desenvolvimento da pessoa, seu preparo para o exercício da cidadania e sua qualificação para o trabalho.

Luckesi ${ }^{05}$ argumenta que "não será certamente a escolarização sozinha que possibilitará aos cidadãos esses níveis de clareza e entendimento. Porém, ela é um instrumental necessário para se chegar a esse patamar de compreensão e de ação". Por essa razão, a Constituição de 1988 confere um tratamento diferenciado e preferencial à educação básica e obrigatória, conforme veremos adiante.

De acordo com Demo ${ }^{06}$, tal preferência à educação básica e obrigatória se justifica da seguinte maneira:

Fundamentalmente nos referimos aqui à educação dita básica, e mais propriamente aos níveis de $1^{\circ}$ grau e pré-escolar, pela razão de que seu conteúdo político é mais evidente. Educação, em si, é sempre ato político, mesmo quando se volta à profissionalização, pelo que também na universidade a função de preparação de elites intelectuais é algo de relevância primordial. Entretanto, nos níveis iniciais, a marca política é preponderante. [...] Se entendermos educação como direito fundamental, pelo menos a nível $1^{\circ}$ grau, decorre sua universalização, ficando a cargo do Estado tal dever.

Na parte inicial do art. 205, a Constituição assevera que a educação é direito de todos e dever do Estado e da família, devendo ser promovida e incentivada com a colaboração da sociedade.

Os princípios que balizam a ministração do ensino estão arrolados nos incisos do art. 206 da CRFB. Trata-se de normas jurídicas principiológicas que explicitam o conteúdo do direito fundamental à educação. Portanto, para que o ensino

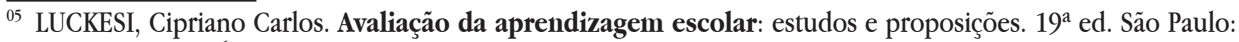
Cortez, 2008. p. 61.

${ }^{06}$ DEMO, Pedro. Educação na nova Constituição: qualidade e democratização. Em Aberto, Brasília, ano 7, n. 39, jul./set., 1988. Disponível em: <http://emaberto.inep.gov.br/index.php/emaberto/article/view/1711/1682> Acesso em: 04 maio 2018. p. 6.
} 
seja ministrado dentro dos parâmetros constitucionais, devem ser respeitados estes princípios: igualdade de condições para o acesso e permanência na escola; liberdade de aprender, ensinar, pesquisar e divulgar o pensamento, a arte e o saber; pluralismo de ideias e de concepções pedagógicas, e coexistência de instituições públicas e privadas de ensino; gratuidade do ensino público em estabelecimentos oficiais; valorização dos profissionais da educação escolar; gestão democrática do ensino público, na forma da lei; garantia de padrão de qualidade; piso salarial profissional nacional para os profissionais da educação escolar pública.

O inciso IV do art. 206 é o que determina que o ensino público em estabelecimentos oficiais seja gratuito. Essa gratuidade, em especial no ensino superior público, possui uma inegável importância estratégica, que é a promoção do inciso II, do mesmo dispositivo: a gratuidade viabiliza a "liberdade de aprender, ensinar, pesquisar e divulgar o pensamento, a arte e o saber", sem amarras de uma privatização alinhada a uma dada corrente ideológica. Estudar em estabelecimento público de graduação ou pós-graduação não pode encerrar a pecha da lobotomia ou mordaça de pensamentos.

A única exceção que a Constituição faz expressamente está em seu art. 242, que dispõe que "o princípio do art. 206, IV, não se aplica às instituições educacionais oficiais criadas por lei estadual ou municipal e existentes na data da promulgação desta Constituição, que não sejam total ou preponderantemente mantidas com recursos públicos."

Perceba-se que, ao lado da gratuidade, a Constituição estabelece a garantia de padrão de qualidade como um dos princípios que regem a ministração do ensino (inciso VII do art. 206). A melhoria da qualidade do ensino, a formação para o trabalho, e a promoção humanística, científica e tecnológica do país são colocadas lado a lado na Constituição, como alvo do Plano Nacional de Educação, para assegurar a manutenção e desenvolvimento do ensino em seus diversos níveis, etapas e modalidades, consoante o art. 214, caput e incisos.

De acordo com o inciso V do art. 208 da Constituição, o dever do Estado com a educação será efetivado mediante a garantia de acesso aos níveis mais elevados do ensino, da pesquisa e da criação artística, segundo a capacidade de cada um. $\mathrm{O}$ art. 23, inciso V, da Carta de Outubro, assevera que proporcionar os meios de acesso à cultura, à educação, à ciência, à tecnologia, à pesquisa e à inovação é competência comum da União, dos Estados, do Distrito Federal e dos Municípios. 
A grande questão é: como ampliar o acesso a um ensino superior de qualidade, diante do atual cenário de escassez de recursos, tendo em vista que a CRFB assevera que a distribuição dos recursos públicos assegurará prioridade ao atendimento das necessidades do ensino obrigatório, que é a educação básica obrigatória e gratuita dos 4 (quatro) aos 17 (dezessete) anos de idade, assegurada inclusive sua oferta gratuita para todos os que a ela não tiveram acesso na idade própria?

$\mathrm{O}$ art. 212 da Constituição dispõe que "a União aplicará, anualmente, nunca menos de dezoito, e os Estados, o Distrito Federal e os Municípios vinte e cinco por cento, no mínimo, da receita resultante de impostos, compreendida a proveniente de transferências, na manutenção e desenvolvimento do ensino". Reza o $\S 3^{\circ}$ que "a distribuição dos recursos públicos assegurará prioridade ao atendimento das necessidades do ensino obrigatório, no que se refere a universalização, garantia de padrão de qualidade e equidade, nos termos do plano nacional de educação" (grifo nosso). Tal disposição, bem como o art. 60 do Ato das Disposições Constitucionais Transitórias (ADCT), em sua redação original e nas redações introduzidas pelas Emendas Constitucionais (EC) $\mathrm{n}^{\circ} 14$, de 1996, e $\mathrm{n}^{0} 53$ de 2006, deixam claro que a prioridade constitucional é a universalização do ensino básico obrigatório, e não do ensino superior.

Nesse sentido, Demo ${ }^{07}$ elucida que, "se respeitado o espírito da lei (e mesmo sua letra), é possível garantir aporte significativo de recursos para a universalização do $1^{\circ}$ grau pelo menos. Resta a tarefa não resolvida do financiamento do $3^{\circ}$ grau, algo que necessita de consideração adequada". Na mesma esteira, Luckesi ${ }^{08}$ assevera que "democratização do ensino implica, em primeiro lugar, democratização do acesso à educação escolar".

Demo ${ }^{09}$ continua explicando que:

A universalização da educação de $1^{\circ}$ grau tem muito a ver com o processo histórico de formação de um povo, entendido este processo como desenvolvimento da qualidade política, ou seja, capacidade histórica de ocupar espaço político e cultural, de se definir e planejar, de se emancipar como sujeito histórico.

\footnotetext{
$\overline{{ }^{07} \text { DEMO, op. cit., p. } 3 .}$

${ }^{08}$ LUCKESI, op. cit., p. 60.

${ }^{09}$ DEMO, op. cit., p. 4.
} 
Luckesi ${ }^{10}$ expressa uma "ineficiência que se torna eficiente", referindo-se ao "ponto de vista de redução ou de impedimento da elevação cultural das camadas populares da sociedade":

Quanto mais ignorância e inconsciência, melhor para os segmentos dominantes da sociedade. Para eles, torna-se necessário controlar o montante de pessoas educadas atendendo às necessidades do modo de produção capitalista. Esse montante, se ultrapassar os limites do controle, poderá gerar desequilíbrio e processos de transformação. A sociedade burguesa procura por diversos mecanismos limitar o acesso e a permanência das crianças e jovens no processo de escolaridade.

Ao determinar essa prioridade, o texto constitucional abre a possibilidade para que todos os cursos de nível superior oferecidos por universidades públicas possam se valer de fontes privadas de financiamento, inclusive a graduação, sem prejuízo da garantia de gratuidade aos que demonstrem que dela necessitam. No art. 213, a CRFB dispõe que nada impede que recursos públicos sejam destinados a instituições de ensino que também captam recursos privados, além do caso do já mencionado art. 242, desde que as instituições de ensino comprovem finalidade não-lucrativa e apliquem seus excedentes financeiros em educação; assegurem a destinação de seu patrimônio a outra escola comunitária, filantrópica ou confessional, ou ao Poder Público, no caso de encerramento de suas atividades.

A universalização da gratuidade em todos os cursos de nível superior oferecidos por universidades públicas é extremamente nociva aos valores e finalidades presentes na nossa Magna Carta. O postulado da proporcionalidade determina que o dever do Estado com a educação de nível superior deve ser efetivado mediante a garantia de acesso à gratuidade, de acordo com a possibilidade de cada um.

Demo ${ }^{11}$ diagnostica que a universidade pública de alta qualidade é ocupada pelos ricos, estando a serviço de interesses privados oligárquicos:

Imaginando-se o Estado como instância equalizadora de oportunidades, seria o lugar mais apropriado de guarda do público, já que diante do Estado todo cidadão possuiria direitos iguais. Todavia, o Estado torna-se, mais facilmente, presa de interesses privados oligárquicos, a menos que seja devidamente

\footnotetext{
$\overline{{ }^{10} \text { LUCKESI, op. cit., p. }} 63$.

${ }^{11}$ DEMO, op. cit., p. 7.
} 
controlado pela cidadania popular organizada. A reivindicação da escola pública deve coincidir com a reivindicação de um Estado público, no sentido de instância delegada de serviço. Caso contrário, se houver escola pública de alta qualidade, será ocupada pelos ricos (caso típico da universidade pública gratuita), continuando, a escola pública "normal", como escola de segunda categoria para gente de segunda categoria (grifo nosso).

Precisamos aqui observar que é inegável que, nos últimos anos, experimentamos uma significativa mudança nesse cenário, mormente em razão das cotas para acesso. Assim, a ideia de que as universidades públicas representam simples nicho elitista do capitalismo ou da direita não condiz com o panorama atual. Contudo, em um quadro de escassez de recursos públicos disponíveis para o ensino público superior, a prioridade deveria ser gastá-los apenas com quem comprovar deles necessitar. Assim, o dever do Estado com a educação mediante a garantia de acesso, segundo a capacidade de cada um, aos níveis mais elevados do ensino seria não apenas efetivado, mas também ampliado.

$\mathrm{Na}$ quarta seção, destacamos uma parte específica deste trabalho para abordarmos a aplicação do princípio da proteção não deficiente à exegese da gratuidade constitucional nas universidades públicas. Antes, porém, nas duas próximas seções, verificaremos na jurisprudência do STF como foram decididos alguns tipos de cobranças em instituições oficiais de ensino público.

\section{A JURISPRUDÊNCIA DO SUPREMO TRIBUNAL FEDERAL}

No julgamento do RE 500.171, de relatoria do ministro Ricardo Lewandowski, o STF reconheceu que a cobrança de matrícula como requisito para que o estudante possa cursar universidade federal viola o art. 206, IV, da Constituição. Consignou-se que o disposto no art. 208 assinala ao Estado a obrigação de manter uma estrutura institucional que permita ao cidadão comum, tenha ou não recursos financeiros, o acesso ao ensino superior, em seus vários níveis ${ }^{12}$.

\footnotetext{
${ }_{12}$ BRASIL. Supremo Tribunal Federal. Recurso extraordinário número 500.171-GO. Universidade Federal de Goiás e Marcos Alves Lopes. Relator Ministro Ricardo Lewandowski. 24 de outubro de 2008. In: Diário da Justiça Eletrônico (Brasília). Disponível em: < http://redir.stf.jus.br/paginadorpub/paginador.jsp?docTP=AC\&docID=557455> Acesso em: 09 jul. 2018.
} 
O STF reconheceu que a gratuidade do ensino público em estabelecimentos oficiais, conforme se lê no art. 206, IV, da CRFB, configura um princípio que não encontra qualquer limitação, no tocante aos distintos graus de formação acadêmica. Assim, a exegese do princípio da gratuidade do ensino público em estabelecimentos oficiais deve amoldar-se à máxima ubilex non distinguit, necinter pres distinguer e debet, ou seja, onde a lei não distingue, não é dado ao intérprete fazê-lo. O STF entendeu que esse princípio deve ser conjugado com o da igualdade de condições para o acesso e permanência na escola, previsto no inciso I do mesmo dispositivo.

Maximiliano ${ }^{13}$ explica assim o brocardo acima:

Quando o texto dispõe de modo amplo, sem limitações evidentes, é dever do intérprete aplicá-lo a todos os casos particulares que se possam enquadrar na hipótese geral prevista explicitamente; não tente distinguir entre as circunstâncias da questão e as outras; cumpra a norma tal qual é, sem acrescentar distinções novas, nem dispensar nenhuma das expressas.

$\mathrm{O}$ resultado desse julgamento deu origem à súmula vinculante $\mathrm{n}^{\mathrm{O}} 12$ do Supremo Tribunal Federal, cujo enunciado dispõe que "a cobrança de taxa de matrícula nas universidades públicas viola o disposto no art. 206, IV, da Constituição Federal"14 . Entendeu-se que caso se admitisse como válida a tese no sentido de que cumpre à sociedade compartilhar com o Estado os ônus do ensino ministrado em estabelecimentos oficiais e da manutenção de seus alunos, eles teriam de contribuir duplamente para a subsistência desse serviço público essencial: uma vez por meio do recolhimento dos impostos e outra mediante o pagamento das mensalidades.

Trata-se de um raciocínio equivocado. Se a gratuidade continuar a ser garantida a todo aquele que demonstre dela carecer, a primazia do interesse público faz com que a existência de recursos públicos disponíveis permaneça necessária, sendo perfeitamente possível a convivência de recursos públicos para custear o ensino gratuito e recursos captados através de mensalidades para custear o ensino de quem não carece de gratuidade. Tais recursos públicos podem conviver com recursos privados, na medida em que, da mesma forma que preceitua o art. 213 e incisos, a finalidade da universidade pública permaneça não lucrativa e seus excedentes financeiros sejam aplicados em educação.

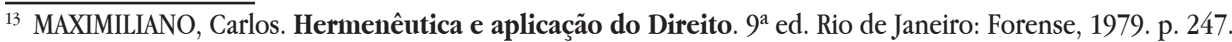

${ }^{14}$ BRASIL. Súmula vinculante número 12. 12 de novembro de 2008. In: Diário de Justiça Eletrônico (Brasília).
} 
Neves ${ }^{15}$ aponta o esgotamento do atual modo de custeio das universidades públicas (por meio do recolhimento dos impostos), ao comentar que apenas 3,5\% do orçamento global das instituições de ensino superior públicas federais são constituídos por recursos diretamente arrecadados, e conclui que:

No momento atual, percebem-se sinais de esgotamento desse modo estabelecido de custeio do ensino superior. [...] O setor público apresenta, também, taxas de evasão o que revela a dificuldade de parte dos alunos de acompanharem os estudos, mesmo sendo gratuito. Esta situação está clara para os órgãos oficiais quando afirmam que o Brasil não poderá depender unicamente da força inercial instalada no sistema.

Os mesmos fundamentos da súmula vinculante $\mathrm{n}^{0} 12$ estão presentes nos julgamentos de dois processos de relatoria do ministro Marco Aurélio. A Primeira Turma do STF reconheceu que não seria possível às universidades públicas a cobrança de taxa para inscrição de processo seletivo seriado, nem para a expedição de diploma. Para o ministro Marco Aurélio, o raciocínio da súmula vinculante $\mathrm{n}^{\mathrm{0}} 12$ também se aplicaria para proibir a cobrança de taxa para participar do vestibular ${ }^{16}$, de taxa de expedição de diploma ${ }^{17}$.

Contudo, convém mencionar que, quando do julgamento do já citado Recurso Extraordinário $n^{0} 500.171$, pelo plenário do STF, os ministros Eros Grau e Celso de Mello trouxeram importantes considerações, para demonstrar que a exigência da gratuidade do ensino não se mostra incompatível com a cobrança de determinadas exações que subsidiem as universidades públicas, tendo em vista as dificuldades por que passam essas instituições em razão da insuficiência de recursos.

Nesse sentido, o ministro Gilmar Mendes deferiu medida liminar para suspender decisão que obrigara universidade federal a abster-se de cobrar a mensalida-

\footnotetext{
$\overline{15}$ NEVES, Clarissa Eckert Baeta. Ensino Superior no Brasil: expansão, diversificação e inclusão. Trabalho apresentado no XXX Congresso da LASA (Associação de Estudos Latino Americanos). São Francisco, Califórnia, 2012. Disponível em: < http://flacso.redelivre.org.br/files/2013/03/1114.pdf> Acesso em: 03 maio 2018. p. 5.

${ }^{16}$ BRASIL. Agravo de instrumento número 748.944-PA. Universidade Federal do Pará e Nathalia Santos Lima. Relator Ministro Marco Aurélio. 26 de agosto de 2014. In: Diário da Justiça Eletrônico (Brasília). Disponível em: <http://stf.jus.br/portal/diarioJustica/verDiarioProcesso.asp?numDj=164\&dataPublicacaoD$j=26 / 08 / 2014$ \&incidente $=3911590 \&$ codCapitulo $=5$ \&numMateria $=114 \&$ codMateria $=2>$ Acesso em: 09 jul. 2018.

${ }^{17}$ BRASIL. Recurso extraordinário número 597.872-RO. Fundação Universidade Federal de Rondônia e Andréa de Sousa Leitão. Relator Ministro Marco Aurélio. 26 de agosto de 2014. In: Diário da Justiça Eletrônico (Brasília). Disponível em: < http://stf.jus.br/portal/diarioJustica/verDiarioProcesso.asp?numDj=164\&dataPublicacaoDj $=26 / 08 / 2014 \&$ incidente $=4558587 \& \operatorname{codCapitulo}=5 \&$ numMateria $=114 \& \operatorname{codMateria}=2>$ Acesso em: 09 jul 2018.
} 
de para os cursos de extensão, argumentando que "a análise dos precedentes desta Suprema Corte que motivaram a aprovação da súmula vinculante $n^{0} 12$ não tratam de qualquer curso realizado pelas universidades públicas, mas apenas dos cursos de ensino superior"18.

Outrossim, quando do exame da medida cautelar na Reclamação 8.295, de relatoria da ministra Rosa Weber, o ministro Gilmar Mendes considerou haver espaço constitucional para compatibilizar a ideia de gratuidade do ensino público com imposições que permitem às instituições universitárias subsidiar os mais carentes. Ele afirmou que a exigência da gratuidade do ensino não se mostra incompatível com a cobrança de determinadas exações que subsidiem as universidades públicas, instituições que continuamente passam por dificuldades em razão da insuficiência de recursos ${ }^{19}$.

O fator de diferenciação do RE $\mathrm{n}^{\mathrm{O}} 597.854 / \mathrm{GO}$, que analisaremos em separado a seguir, é o espaço de conformação existente no texto constitucional para a definição de quais atividades integram o conceito de manutenção e desenvolvimento do ensino, que, segundo o relator, ministro Edson Fachin, é o parâmetro constitucional para a destinação com exclusividade dos recursos públicos. Entendeu-se ser impossível afirmar, a partir de uma leitura estrita da Constituição, que as atividades de pós-graduação são abrangidas pelo conceito de manutenção e desenvolvimento do ensino.

\section{A DECISÃO DO STF NO RE No $597.854 /$ GO}

A questão da cobrança por universidades públicas de mensalidade em cursos de especialização chegou ao STF pela via do $\mathrm{RE}^{0}{ }^{0} 597.854$. O recurso teve como relator o ministro Edson Fachin. O recorrente aduziu que a gratuidade prevista no

\footnotetext{
${ }_{18}$ BRASIL. Reclamação número 8.596-CE. Universidade Federal do Ceará e Juíza Federal da 4a Vara Federal da Seção Judiciária do Ceará. Relator Ministro Carlos Britto. 05 de agosto de 2009. In: Diário da Justiça Eletrônico (Brasília). Disponível em: < http://stf.jus.br/portal/diarioJustica/verDiarioProcesso.asp?numDj=146\&dataPublicacaoDj $=05 / 08 / 2009 \&$ incidente $=3719741 \&$ codCapitulo $=6 \&$ numMateria $=103 \&$ codMateria $=10>$ Acesso em: 09 jul 2018.

${ }^{19}$ BRASIL. Reclamação número 8.295-RS. Universidade Federal do Rio Grande do Sul e Tribunal Regional Federal da $4^{a}$ Região. Relatora Ministra Rosa Weber. 04 de agosto de 2009. In: Diário da Justiça Eletrônico (Brasília). Disponível em: <http://stf.jus.br/portal/diarioJustica/verDiarioProcesso.asp?numDj=146\&dataPublicacaoD$j=05 / 08 / 2009 \&$ incidente $=3702571 \&$ codCapitulo $=6 \&$ numMateria $=103 \&$ codMateria $=10>$ Acesso em: 09 jul. 2018.
} 
art. 206, IV, da CRFB, refere-se ao ensino básico obrigatório. De fato, Duarte ${ }^{20}$ ensina que "em síntese, a educação, como direito fundamental de caráter social: [...] d) pertence a todos, mas deve priorizar categorias de pessoas que se encontram numa mesma posição de carência ou vulnerabilidade". A seguinte tese foi fixada nesse julgamento, apreciando o tema 535 da repercussão geral: "A garantia constitucional da gratuidade de ensino não obsta a cobrança por universidades públicas de mensalidade em cursos de especialização". No entanto, o STF não enfrentou a questão relativa à possibilidade de cobranças em cursos de graduação e de pós-graduação stricto sensu. Analisaremos agora os principais argumentos dos ministros.

De acordo com o argumento trazido pelo ministro Ricardo Lewandowski, os cursos de graduação e de pós-graduação stricto sensu, que são os cursos que conferem graus acadêmicos de bacharel, mestre e doutor, se diferenciam da pós-graduação lato sensu, em virtude da titulação que conferida ao discente (esta não confere um grau acadêmico, mas simplesmente um certificado, então, ela constitui um serviço extraordinário das universidades, compatível com sua autonomia didático-científica - art. 207, CRFB).

Nesse sentido, a lei de diretrizes e bases da educação nacional (Lei n ${ }^{\circ} 9.394$ de 1996) e o parecer do Conselho Nacional da Educação no 364/2002/CNE/CES esclarecem que há distinção relevante entre os cursos de graduação, de pós-graduação stricto sensu e os de pós-graduação lato sensu. Segundo o parecer, nos cursos de pós-graduação lato sensu, as universidades públicas não só podem como devem realizar a cobrança, "visto que não se espera que as universidades públicas destinem recursos públicos para tarefas que não fazem parte de sua missão constitucional, para a qual, e somente para esta, está preceituada a gratuidade". Não obstante isso, o parecer afirma que "ignorar esta circunstância e as prioridades sociais a serem contempladas implicaria transferência de recursos exíguos e, em certo sentido, inelásticos para a sustentação de atividades assessórias, em prejuízo das suas funções mais relevantes".

O ministro Gilmar Mendes diverge do ministro Lewandowski em um ponto específico. Para aquele ministro, todos os cursos de pós-graduação se inserem no conceito de extensão, como a própria nomenclatura sugere ("pós-"). Assim, até mesmo os cursos de mestrado e de doutorado acadêmico correspondem a uma extensão da graduação. Logo, nenhuma forma de pós-graduação seria a priori necessariamen- 
te gratuita. Em seu voto, Mendes assinalou que:

Não há nada que obrigue a União ou suas instituições de ensino superior a oferecerem cursos de pós-graduação, mormente na modalidade lato sensu. Logo, se optam por oferecer, se optam por ir além do que a Constituição lhes impõe, é natural que recorram ao implemento de mecanismos especiais de financiamento, tal como a cobrança de mensalidade ${ }^{21}$.

O ministro Alexandre de Moraes argumentou que os professores das universidades públicas acabam dando aula em cursos de especialização nas universidades privadas, ao invés de montar esses cursos nas universidades públicas. Assim, não entra para a universidade pública esse dinheiro que poderia ser investido na graduação, liberando, desse modo, o Poder Público para investir mais recursos no ensino obrigatório.

A ministra Rosa Weber mencionou outro dado: a não oferta desses cursos de pós-graduação pelas universidades públicas traz prejuízo considerável à sociedade, pois, além de haver grande procura pelas vagas, muitos deles oferecem à comunidade, de forma gratuita, ou praticamente a preço de custo, atendimento feito pelos alunos, especialmente na área da saúde, estando presente o interesse social.

A isso se soma o argumento do ministro Luís Roberto Barroso de que os recursos públicos destinados às universidades serão sempre insuficientes. Como o conhecimento é ilimitado, recursos para o conhecimento nunca serão o bastante. Desse modo, a universidade precisa ter mecanismos de autossustentação, de autofinanciamento, ainda mais em um país pobre como o nosso, em que faltam recursos para o básico. Portanto, é preciso usar inteligência criativa e pensamento original para melhorar o sistema de universidade pública no Brasil. Como dinheiro não nasce em árvore, qualquer fonte legítima e transparente de recursos para as universidades é bem-vinda.

O STF, portanto, considerou que as dificuldades econômicas por que passam nossas universidades públicas justificam a busca de mecanismos alternativos de financiamento como a remuneração pela prestação de serviços educacionais através de cursos de especialização. Concluiu-se, por maioria, que há espaço constitucional para compatibilizar a ideia de gratuidade do ensino público com mecanismos que permitam às instituições universitárias públicas subsidiar parte de suas despesas.

$\overline{{ }^{21} \text { BRASIL, op. cit., p. } 99 .}$ 
Carvalho ${ }^{22}$ lembra o motivo pelo qual a cobrança de mensalidades em instituições públicas ainda não foi implementada, apesar de possibilitar maior equidade e eficiência no sistema:

Esta questão polêmica sofreu pressões políticas no âmbito do Poder Legislativo que impediram que fosse levada à votação. [...] A extinção da gratuidade nas instituições públicas está na agenda governamental desde a Reforma Universitária de 1968. Ainda que os documentos oficiais indicassem a necessidade da cobrança de mensalidades, este ponto foi sendo retirado da legislação final, como produto do consenso e acomodação de interesses divergentes (grifo nosso).

Por outro lado, no voto vencido, o ministro Marco Aurélio afirmou que ao se permitir que as universidades públicas cobrem mensalidades, o ensino deixa de ser público, e passa a ser híbrido:

Tendo-se a um só tempo, sob o ângulo da natureza jurídica, universidade pública e privada. Ela é pública no tocante a certo aspecto, mas é privada no tocante a outro, ao se estabelecer que pode atuar como se fosse um ente de educação privado, obstaculizando-se o acesso universal, levando em conta os mais e os menos favorecidos, a viabilizar, ante o mérito, o acesso dos que não podem pagar ${ }^{23}$.

Para ele, essa possibilidade de cobrança violaria o princípio da igualdade de condições para acesso e permanência no ensino. A porta de acesso ao aperfeiçoamento universitário estaria, pois, fechada aos menos afortunados. Contudo, a possibilidade de cobrança promove justamente o contrário: a ampliação do acesso a um ensino superior público de maior qualidade. A reinterpretação do princípio da gratuidade que propomos aqui faz com que a porta de acesso ao aperfeiçoamento universitário esteja sempre aberta aos menos afortunados, que demonstrem necessitar dessa garantia, não havendo que se falar em violação do princípio da igualdade de condições para acesso e permanência no ensino.

O fato de ser admitida a cobrança de mensalidades não torna as universida-

\footnotetext{
${ }^{22}$ CARVALHO, Cristina Helena Almeida de. Política para o ensino superior no Brasil (1995-2006): Ruptura e continuidade nas relações entre público e privado. In: SILVA JÚNIOR, João dos Reis; OLIVEIRA, João Ferreira de; MANCEBO, Deise (Org.). Reforma universitária: dimensões e perspectivas. Campinas: Alínea, 2006. p. 128.

${ }^{23}$ BRASIL, op. cit., p. 103.
} 
des públicas em instituições privadas, desde que os recursos sejam reinvestidos no interesse público, em especial na melhoria da qualidade de ensino e na ampliação do acesso isonômico às vagas, não havendo, portanto, objetivo de lucros. O superior interesse público deve continuar predominando nas instituições oficiais de ensino superior, a despeito de se permitir a exigência de contraprestação aos alunos que podem pagá-la.

A universidade pública gratuita precisa continuar a existir, conforme ensina Carvalho $^{24}$ :

A população de baixa renda não necessita apenas de gratuidade integral ou parcial para estudar, mas de condições que apenas as instituições públicas, ainda, podem oferecer, tais como: transporte, moradia estudantil, alimentação subsidiada, assistência médica disponível nos hospitais universitários, bolsas de pesquisa, entre outros.

Valores e objetivos constitucionais estão sendo feridos ao se permitir que a gratuidade seja universal. O ministro Luiz Fux, na fundamentação do seu voto, ressaltou que, quando se trata de direitos fundamentais, deve-se buscar sua máxima efetividade, bem como que, quando se trata de direitos sociais, a proibição à proteção insuficiente pauta a extensão da obrigação positiva que pode ser exigida do Estado:

$\overline{{ }^{24} \text { CARVALHO, op. cit. }}$ p. 137.

A melhor interpretação dos dispositivos constitucionais que tratam do direito à educação não pode ser aquela que conduz ao sucateamento da prestação do serviço público, com o evidente e imediato prejuízo do alunado e da sociedade. Ora, o direito social à educação pública deve ser interpretado de forma a atender à sua máxima efetividade, o que corresponde ao atendimento dos princípios e diretrizes dispostos pelo constituinte. A interpretação literal e isolada do artigo 206, IV, da Constituição prejudica o acesso universal a uma educação pública de excelência, esvaziando o conteúdo dos outros dispositivos aqui mencionados. Não se trata do argumento consequencialista da crise financeira e do sucateamento, que merece também o devido destaque, mas da concordância prática dos dispositivos constitucionais que tratam especificamente do direito à educação. A interpretação que, sob as vestes de uma pretensa proteção ao alunado, impõe a exclusividade de recur- 
sos públicos ao financiamento de cursos de pós-graduação em universidades públicas, em um contexto notório de escassez e sucateamento da educação em todos os níveis, é financeiramente irresponsável e nocivo à prestação do próprio direito. [...] Dessa forma, tem-se que a atuação do legislador, ainda que constituinte, deve ser pautada pelo propósito de assegurar a máxima efetividade do direito fundamental. Tratando-se de direitos sociais, a proibição à proteção insuficiente pauta a extensão da obrigação positiva que pode ser exigida do Estado. No caso, a restrição absoluta a qualquer forma de financiamento privado em universidades públicas, sem que tenha sido essa a vontade manifestada pelo constituinte originário, sequer contribui para um outro objetivo legítimo. Ainda que o fizesse, a possibilidade de se conceder bolsas, isenções ou empréstimos atenderia ao dever estatal de assegurar a equalização de oportunidades educacionais, o acesso aos níveis mais elevados de educação e formação para o trabalho, consistindo em meio menos prejudicial ao direito à educaçãa ${ }^{25}$.

A seguir, analisaremos com mais profundidade o princípio que proíbe tal proteção deficiente e como ele exige que a cláusula da gratuidade seja reinterpretada, para que o ensino público nos estabelecimentos oficiais, inclusive na graduação, seja gratuito apenas àqueles que demonstrem necessitar de tal benefício.

\section{O PRINCÍPIO DA PROTEÇÃO NÃO DEFICIENTE}

Nesta seção, buscaremos a resposta da seguinte questão: a cobrança de valores relativos a cursos de graduação e pós-graduação stricto sensu em universidades públicas não fere a Constituição? Para tanto, analisaremos a aplicação do princípio da proteção não deficiente à exegese do princípio da gratuidade.

Segundo Sarlet ${ }^{26}$, os princípios fundamentais constituem-se no núcleo essencial da Constituição material. São normas que dão base e que informam toda ordem constitucional.

Sarlet ${ }^{27}$ assinala, ainda, que:

\footnotetext{
$\overline{{ }^{25} \text { BRASIL, op. cit., p. } 61-62 .}$

${ }^{26}$ SARLET, Ingo Wolfgang. A eficácia dos direitos fundamentais. 2. ed. Porto Alegre: Livraria do Advogado, 2001, p. 99.

${ }^{27}$ Ibid, p. 394.
} 
Situações de colisão de direitos fundamentais afiguram-se cada vez mais frequentes na prática jurídica brasileira devido ao alargamento do âmbito e da intensidade de proteção dos direitos fundamentais levado a cabo pela Constituição Federal de 1988, notadamente em função do já referido caráter analítico do catálogo constitucional de direitos.

Alexy $^{28}$ sustenta que princípios são normas que ordenam que algo seja realizado na maior medida possível dentro das possibilidades jurídicas e fáticas existentes. Princípios são mandamentos de otimização que se caracterizam pelo fato de serem concretizados em graus variados. A medida devida da satisfação dos princípios não depende apenas das possibilidades fáticas, mas também das possibilidades jurídicas. O âmbito das possibilidades jurídicas é delimitado pelos princípios e regras colidentes.

Dworkin $^{29}$ ensina que princípios não apresentam consequências jurídicas que se seguem automaticamente quando as condições são dadas. Enunciam uma razão que conduz o argumento em uma certa direção, mas necessitam de uma decisão particular. Pode haver outros princípios ou outras políticas que argumentam em uma ou outra direção. Se assim for, o princípio pode não prevalecer, mas isso não significa que não se trate de um princípio do nosso sistema jurídico, pois em outro caso, quando essas considerações estiverem ausentes ou tiverem menos força, o princípio poderá ser decisivo para a tomada da decisão. Ao afirmarmos que um princípio particular é um princípio do nosso Direito, isso significa que, se ele for relevante, ele deve ser levado em conta pelas autoridades públicas, como uma razão que inclina numa ou noutra direção. Quando princípios se intercruzam, temos que levar em conta a força relativa de cada um, e esse juízo frequentemente será objeto de controvérsia, pois não há uma mensuração exata, mas essa mensuração é parte integrante do conceito de princípio.

A hermenêutica constitucional é quem fornece os recursos necessários para a mais adequada interpretação do texto constitucional, preservando a supremacia, a unidade e a efetividade da constituição, através dos princípios instrumentais da interpretação constitucional. Entre eles está o princípio da razoabilidade ou da proporcionalidade. O magistrado, na sua missão de dizer o Direito, deve estar atento aos novos paradigmas e categorias da interpretação constitucional.

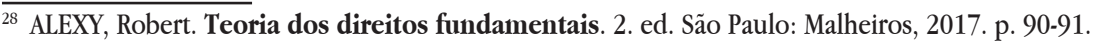

${ }^{29}$ DWORKIN, Ronald Myles. Levando os direitos a sério. 2. ed. São Paulo: Martins Fontes, 2010. p. 40.
} 
Barroso $^{30}$ ensina que vivenciamos hodiernamente um novo direito constitucional, que vem sendo construído desde a redemocratização e que possui como marco filosófico a construção do pós-positivismo. Dentre as principais mudanças de paradigma, destaca-se a força normativa da Constituição e a reelaboração doutrinária da interpretação constitucional. O princípio da razoabilidade ou da proporcionalidade e a técnica da ponderação ganharam papel principal na solução de conflitos entre princípios constitucionais. O princípio da proporcionalidade, no Brasil, é produto da conjugação da doutrina do devido processo legal substantivo do direito norte-americano e do princípio da proporcionalidade do direito alemão. A razoabilidade, nos Estados Unidos, funcionou como critério de aferição de constitucionalidade das leis, enquanto que a proporcionalidade, na Alemanha, evoluiu a partir do direito administrativo, como mecanismo de controle dos atos do Executivo. Sem embargo da origem e do desenvolvimento diversos, um e outro abrigam os mesmos valores subjacentes: racionalidade, justiça, medida adequada, senso comum, rejeição aos atos arbitrários ou caprichosos.

Barroso $^{31}$ elucida que o princípio da proporcionalidade exige que as decisões sejam tomadas conforme a razão, supondo equilíbrio, moderação e harmonia, devendo corresponder ao senso comum e aos valores vigentes. O princípio funciona como um critério de ponderação entre proposições constitucionais que estabeleçam tensões entre si ou que entrem em rota de colisão. O raciocínio silogístico da subsunção, no qual uma premissa maior (a norma) incide sobre uma premissa menor (os fatos) produzindo uma conclusão que é o fruto da aplicação da norma ao caso concreto, não é suficiente para lidar com as situações que envolvam colisões de princípios ou de direitos fundamentais. Nesses casos, há várias premissas maiores e apenas uma menor, e, se aplicarmos a subsunção, estaremos elegendo uma única premissa maior e descartando as demais. Isso não seria constitucionalmente adequado, por violar o princípio da unidade da Constituição. Então, os múltiplos elementos em jogo devem ser considerados na medida de sua importância e pertinência para o caso concreto, através da técnica da ponderação. O princípio da proporcionalidade é o fio condutor de todo esse processo.

Infelizmente, hoje, quase trinta anos após a promulgação da CRFB, as universidades públicas estão sucateadas. O poder público não tem mais dinheiro para

\footnotetext{
${ }^{30}$ BARROSO, Luís Roberto. Curso de direito constitucional contemporâneo: os conceitos fundamentais e a construção do novo modelo. São Paulo: Saraiva, 2009. p. 255.

${ }^{31}$ Ibid, p. 333.
} 
quase nada e as universidades públicas se encontram à deriva. Diante dessa escassez, estamos no momento oportuno de se fazer uma reinterpretação da cláusula de gratuidade, para afastarmos uma exegese financeiramente irresponsável e nociva à prestação do próprio Direito.

Em seu voto no RE 597854-GO, o ministro Barroso argumenta que:

Na vida, tudo que não esteja funcionando bem deve ser objeto de algum tipo de reflexão e de diagnóstico adequado para que se adotem políticas públicas adequadas. [...] Portanto, nós precisamos, corajosamente, fazer um diagnóstico a propósito da universidade pública no Brasil, porque a regra é que existam greves, e greve, evidentemente, é um recurso extremo quando as negociações não funcionam. Portanto, nós temos um sistema que todo ano deixa de funcionar. Alguma coisa está errada e, portanto, é preciso, eu penso, que as melhores cabeças se debrucem sobre o problema da universidade pública, para detectar os problemas e propor as soluções. Sem preconceitos. Estudar, ver as alternativas e escolher um caminho ${ }^{32}$.

Adotar uma interpretação do princípio da gratuidade do ensino que agrava esse quadro de sucateamento da universidade pública e inviabiliza a sua reversão é uma violação do princípio da proteção não deficiente, uma das faces do princípio da proporcionalidade.

Streck ${ }^{33}$ ensina que o princípio da proteção não deficiente é uma exigência do direito constitucional contemporâneo de implicações práticas na formulação, interpretação e aplicação das leis:

Se a Constituição estabelece que o Brasil é uma República Federativa, que se institui como Estado Democrático de Direito, é porque, seguindo o moderno constitucionalismo, fica implícito que estamos diante de uma Constituição normativa e dirigente. Isto, à evidência, acarreta compromissos e inexoráveis consequências no campo da formulação, interpretação e aplicação das leis.

\footnotetext{
${ }_{32}$ BRASIL, op. cit., p. 66.

${ }^{33}$ STRECK, Lenio Luiz. A dupla face do princípio da proporcionalidade: da proibição de excesso (übermassverbot) à proibição de proteção deficiente (untermassverbot) ou de como não há blindagem contra normas penais inconstitucionais. Revista da Ajuris, Porto Alegre, v. 32, n. 97, p. 172-201, mar. 2005. p. 184.
} 
Para Sarlet ${ }^{34}$, a violação da proibição de insuficiência encontra-se habitualmente representada por uma omissão (ainda que parcial) do poder público, no que diz respeito ao cumprimento de um imperativo constitucional.

Gavião $0^{35}$ leciona que "na medida em que o Estado se omite em seu dever de proteção de direitos fundamentais, ou não o faz de forma adequada e eficaz, seu ato estará eivado de inconstitucionalidade, por violação da proibição de proteção deficiente".

Sarmento e Souza Neto ${ }^{36}$ ensinam que a ideia de proporcionalidade como proteção não deficiente desenvolveu-se no direito constitucional germânico a partir da concepção de que os direitos fundamentais possuem uma "dimensão objetiva", na medida em que tutelam certos bens jurídicos e valores que devem ser promovidos, havendo, portanto, um "dever de proteção", um "imperativo de tutela". Essa proibição de proteção deficiente estende-se ao Legislativo, à Administração Pública e ao Poder Judiciário, que podem ser controlados, através do manejo do princípio da proporcionalidade, de forma a coibir a inação ou atuação deficiente dos Poderes da República.

Silva ${ }^{37}$ afirma que o princípio da proporcionalidade assevera que não devemos nos deixar levar ao exagero do excesso, nem ao ponto de se omitir por completo (garantindo, assim, um dever de proteção ao menos básico), dando ao operador uma espécie de zona de conformação para garantir, efetivar e proteger direitos fundamentais. Nessa zona de conformação, o excesso, além da falta do mínimo, é igualmente fiscalizado e reprimido pela jurisdição constitucional.

Mais que um limite, a constitucionalização dos direitos faz com que entendamos a Constituição como fundamento do Direito. O fundamento e o sentido da cláusula da gratuidade do ensino público estão na própria Constituição. Analisar o direito à gratuidade do ensino sob a ótica do Estado Democrático de Direito e do neoconstitucionalismo implica levar em conta as mudanças paradigmáticas ocorridas no campo do Estado e do Direito. Isso demanda uma reinterpretação axiológica

\footnotetext{
${ }^{34}$ SARLET, Ingo Wolfgang. Constituição e proporcionalidade: o direito penal e os direitos fundamentais entre a proibição de excesso e de insuficiência. Revista da Ajuris, Porto Alegre, v. 32, n. 98, p. 105-150, jun. 2005. p. 132.

${ }^{35}$ GAVIÃO, Juliana Venturella Nahas. A proibição de proteção deficiente. Revista do Ministério Público do RS, Porto Alegre, n. 61, p. 93-111, maio/out. 2008. p. 101.

36 SOUZA NETO, Cláudio Pereira de; SARMENTO, Daniel. Direito constitucional: teoria, história e métodos de trabalho. $1^{\text {a }}$ reimpr. Belo Horizonte: Fórum, 2013. p. 481.

${ }^{37}$ SILVA, Jorge Pereira da. Interdição de Protecção Insuficiente, proporcionalidade e conteúdo essencial. In: FACULDADE DE DIREITO DA UNIVERSIDADE DE LISBOA. Estudos de Homenagem ao Prof. Doutor Jorge Miranda. Volume II. Direito Constitucional e Justiça Constitucional. Coimbra: Coimbra Editora, 2012. p. 360.
} 
e teleológica do princípio da gratuidade.

A interpretação do princípio da gratuidade não pode inviabilizar a garantia constitucional da melhoria de qualidade do ensino, prevista no inciso VII, do art. 206, e no art. 214, caput e incisos. Não podemos ignorar o $\S 3^{\circ}$ do art. 212 , que preconiza que "a distribuição dos recursos públicos assegurará prioridade ao atendimento das necessidades do ensino obrigatório, no que se refere a universalização, garantia de padrão de qualidade e equidade, nos termos do plano nacional de educação".

Em um mundo ideal, com orçamento excedente, em que a graduação fosse bem suprida de recursos, não haveria a necessidade de cobrança nenhuma em instituições públicas, pois é obrigação do Poder Público ampliar o orçamento das universidades públicas para que elas possam oferecer seus cursos. Contudo, infelizmente, a realidade é diferente. Falta dinheiro nas universidades para o básico, como conservação e limpeza, o que é público e notório.

Existe, ainda, um dever de progressiva ampliação do acesso ao ensino superior, de acordo com os incisos V do art. 208 e do art. 23, da Carta de Outubro.

Portanto, o direito ao ensino gratuito precisa ser interpretado conforme os objetivos desenhados pela Constituição, sendo certo que nenhum valor, por mais importante que seja, pode ser imposto arbitrariamente ao preço de se anular o núcleo existencial dos demais. Se entendermos que a gratuidade do ensino público obsta a cobrança de mensalidades em universidades públicas, valores de grande relevância, como a ampliação do acesso ao ensino superior e a melhoria da qualidade desse ensino, serão praticamente aniquilados, ao invés de equilibrar com bom senso e harmonia os interesses constitucionais, preservando a unidade da Constituição e o núcleo essencial desses direitos.

Há ainda o argumento em favor do princípio da isonomia. Ruy Barbosa $a^{38}$ assevera que: "a regra da igualdade não consiste senão em quinhoar desigualmente aos desiguais, na medida em que se desigualam". Algo extremamente antidemocrático e antirrepublicano é permitir que um sistema funcione para favorecer os ricos em detrimento dos mais pobres. Isso é atentar contra a ideia de Estado democrático de Direito. O Direito não pode constituir privilégios e, no seu papel de interpretar a Constituição, o magistrado não pode escolher o sentido que promove um sistema perverso e seletivo. Interpretando-se axiológica e teologicamente a Constituiçãa,

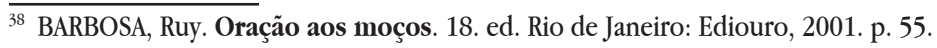


devemos afastar o significado que iguala desiguais e, assim, distorce os valores e os fins do princípio da gratuidade, impedindo que o acesso ao ensino superior gratuito e de qualidade seja ampliado aos menos afortunados.

Admitir que quem pode pagar pague por cursos oferecidos nas universidades públicas permite que mais vagas sejam ofertadas para aqueles que não têm condições de pagar. Em outros países, como a Alemanha, por exemplo, é comum ter turmas com centenas de alunos. Aqui no Brasil conservamos no ensino universitário público uma estrutura que disponibiliza o acesso a muito poucos, e, dentre esses poucos, muitos são os que podem pagar as mensalidades, o que reduz as chances de acesso de quem não pode pagar, restando por ferida a isonomia.

Para preservação do núcleo essencial do direito à gratuidade e afastamento da proteção deficiente dos direitos fundamentais em rota de colisão, é necessária a aplicação da técnica de ponderação de interesses. Ao ponderarmos os interesses em jogo no conflito entre gratuidade e isonomia, melhoria da qualidade do ensino e ampliação do acesso a cursos de nível superior, aplicando-se os três elementos ou requisitos da proporcionalidade (necessidade, adequação e proporcionalidade em sentido estrito), a conclusão lógica e razoável é que, em cursos de nível superior, a gratuidade precisa ser relativizada, para ser usufruída apenas por aqueles que comprovadamente necessitem dela. Tal relativização da gratuidade é medida necessária, adequada e proporcional para se proteger de maneira não deficiente a isonomia, a melhoria da qualidade e a ampliação de acesso ao ensino superior do nosso país, que são verdadeiros mandamentos de otimização em relação às possibilidades fáticas e jurídicas.

A medida é idônea, pois o meio promove o fim. A cobrança de mensalidades nas universidades públicas faz com que ela disponha de mais recursos para investir na melhoria da qualidade do ensino que ela oferece e no incremento da quantidade de vagas, ampliando, assim, o acesso de forma isonômica.

Tal medida é necessária, pois a melhoria da qualidade, a ampliação do acesso e a isonomia no ensino superior público não podem ser obtidas por outros meios que afetem menos o indivíduo, a não ser a captação de recursos privados daqueles que podem pagar pelos cursos, já que a prioridade dos recursos públicos é a educação obrigatória e tais recursos são sempre limitados.

Por fim, ela é proporcional em sentido estrito, pois na medida em que a gratuidade continua a ser garantida para aqueles que demonstram que dela necessitam, 
é possível alcançar um equilíbrio entre o grau de afetação do direito à gratuidade e o objetivo pretendido, que é melhoria da qualidade do ensino, ampliação do acesso e isonomia.

Essa interpretação da garantia de gratuidade do ensino público que defendemos aqui também deve levar em conta as consequências positivas geradas no mercado. Possibilitar que as universidades públicas possam oferecer cursos remunerados acaba fazendo com que haja uma queda no preço praticado pelo mercado, porque na universidade pública o preço nunca será o mesmo da universidade privada, porque aquela não visa lucro. A interpretação da cláusula da gratuidade no sentido da inconstitucionalidade da cobrança acaba jogando praticamente todo esse mercado nas mãos das universidades privadas, o que, logicamente, faz com que o preço suba. Outro aspecto importante a ser levado em consideração nessa interpretação é o incremento da qualidade do ensino promovido pela concorrência, que deve ser estimulada. Quanto mais cursos houver no mercado, mais competitivas serão as alternativas aos cidadãos.

Por essas razões, a relativização do princípio da gratuidade em instituições públicas de ensino superior abordada neste trabalho não fere a Constituição de 1988. O que jamais se pode perder é a noção de que o ensino superior público transcende a questão de gratuidade: o ensino público superior (e também o privado) deve trazer resultados para a sociedade, isto é, propor soluções para a coletividade a que está integrado, como, por exemplo, estudar soluções para combater a fome e superar a violência estrutural. Em suma, público ou privado, o ensino pertence à sociedade.

Por fim, outra possibilidade interessante é o estabelecimento de contrapartidas, monetárias ou não, aos alunos do ensino público superior gratuito. Contudo, é necessária a fixação de critérios legais para isso, o que não compete ao STF, mas sim ao Poder Legislativo.

\section{CONSIDERAÇÕES FINAIS}

Procuramos ao longo deste trabalho desenvolver a ideia de que a exegese do princípio da gratuidade do ensino público em estabelecimentos oficiais de nível superior precisa ser revista. Concluiu-se que a cobrança em cursos de pós-graduação 
stricto sensu e de graduação não fere a Constituição, apesar do princípio constitucional da gratuidade do ensino público em estabelecimentos oficiais.

Vimos que a Constituição da República adota como valores e objetivos a melhoria da qualidade do ensino e a ampliação do acesso a cursos de nível superior, bem como que esse acesso deve ser, entre outras coisas, isonômico. Como a hermenêutica constitucional deve observar o postulado da proporcionalidade, interpretações que promovem proteção deficiente de valores e objetivos constitucionais necessitam de ser repensadas.

No atual quadro de sucateamento e escassez em que se encontram as universidades públicas, e diante da prioridade dada pela Constituição ao ensino obrigatório, interpretar como sendo universal a gratuidade do ensino superior público viola o princípio da proibição da proteção deficiente. Uma aplicação adequada dos três elementos ou requisitos da proporcionalidade (adequação, necessidade e proporcionalidade em sentido estrito), que compatibiliza a gratuidade com a isonomia, com a melhoria da qualidade do ensino e com a ampliação do acesso a cursos de nível superior, nos leva à conclusão de que só devem fazer jus a essa gratuidade aqueles que demonstrem que dela necessitam.

Concluiu-se que a gratuidade deve ser universal na educação básica, como determina a Constituição, que expressamente garante que a educação básica é obrigatória e gratuita dos 4 (quatro) aos 17 (dezessete) anos de idade, assegurada inclusive sua oferta gratuita para todos os que a ela não tiveram acesso na idade própria. Outrossim, a Constituição da República assevera que a distribuição dos recursos públicos assegurará prioridade ao atendimento das necessidades desse ensino. Ao determinar essa prioridade, o texto constitucional abre a possibilidade para que o ensino superior promovido pelas universidades públicas possa se valer de fontes privadas de financiamento em todos os seus cursos, seja graduação, seja especialização, seja mestrado e doutorado, sem prejuízo da garantia de gratuidade aos que demonstrem que dela necessitam. Assim, preserva-se o núcleo essencial do direito à gratuidade e afasta-se a proteção deficiente dos direitos fundamentais em rota de colisão. 


\section{REFERÊNCIAS}

ALEXY, Robert. Teoria dos direitos fundamentais. 2. ed. São Paulo: Malheiros, 2017.

BARBOSA, Ruy. Oração aos moços. 18. ed. Rio de Janeiro: Ediouro, 2001.

BARROSO, Luís Roberto. Curso de direito constitucional contemporâneo: os conceitos fundamentais e a construção do novo modelo. São Paulo: Saraiva, 2009.

BRASIL. Constituição da República Federativa do Brasil de 1988. Diário Oficial da República Federativa do Brasil, Brasília, 5 out. 1988. Disponível em: <http:// www.planalto.gov.br/ccivil_03/constituicao/constituicaocompilado.htm > Acesso em: 09 jul. 2018.

BRASIL. Lei no ${ }^{\circ}$ 9.394, de 20 de dezembro de 1996. Estabelece as diretrizes e bases da educação nacional. Diário Oficial da República Federativa do Brasil, Brasília, 23 dez. 1996. Disponível em: < http://www.planalto.gov.br/ccivil_03/LEIS/19394. htm> Acesso em: 09 jul. 2018.

BRASIL. Supremo Tribunal Federal. Recurso extraordinário número 500.171-GO. Universidade Federal de Goiás e Marcos Alves Lopes. Relator Ministro Ricardo Lewandowski. 24 de outubro de 2008. Diário da Justiça Eletrônico, Braślia. Disponível em: $<$ http://redir.stf.jus.br/paginadorpub/paginador.jsp?docTP=AC\&docID=557455> Acesso em: 09 jul. 2018.

BRASIL. Súmula vinculante número 12. 12 de novembro de 2008. In: Diário de Justiça Eletrônico (Brasília). Disponível em: < http://www.stf.jus.br/ portal/cms/verTexto.asp?servico $=$ jurisprudenciaSumulaVinculante $>$ Acesso em: 09 jul. 2018.

BRASIL. Reclamação número 8.295-RS. Universidade Federal do Rio Grande do Sul e Tribunal Regional Federal da $4^{a}$ Região. Relatora Ministra Rosa Weber. 04 de agosto de 2009. Diário da Justiça Eletrônico, Brasília. Disponível em: <http://stf. jus.br/portal/diarioJustica/verDiarioProcesso.asp?numDj $=146 \&$ dataPublicacaoD$j=05 / 08 / 2009$ \&incidente $=3702571 \&$ codCapitulo $=6 \&$ numMateria $=103 \&$ codMateria $=10>$ Acesso em: 09 jul. 2018. 
BRASIL. Reclamação número 8.596-CE. Universidade Federal do Ceará e Juíza Federal da $4^{\mathrm{a}}$ Vara Federal da Seção Judiciária do Ceará. Relator Ministro Carlos Britto. 05 de agosto de 2009. Diário da Justiça Eletrônico, Brasília. Disponível em: < http://stf.jus.br/portal/diarioJustica/verDiarioProcesso.asp?numDj=146\&dataPublicacaoDj $=05 / 08 / 2009$ \&incidente $=3719741 \&$ codCapitulo $=6 \&$ numMateria $=103 \&$ codMateria $=10>$ Acesso em: 09 jul. 2018.

BRASIL. Recurso extraordinário número 597.872-RO. Fundação Universidade Federal de Rondônia e Andréa de Sousa Leitão. Relator Ministro Marco Aurélio. 26 de agosto de 2014. Diário da Justiça Eletrônico, Brasília. Disponível em: < http://stf. jus.br/portal/diarioJustica/verDiarioProcesso.asp?numDj=164\&dataPublicacaoD$j=26 / 08 / 2014 \&$ incidente $=4558587 \&$ codCapitulo $=5 \&$ numMateria $=114 \&$ codMateria $=2>$ Acesso em: 09 jul. 2018.

BRASIL. Agravo de instrumento número 748.944-PA. Universidade Federal do Pará e Nathalia Santos Lima. Relator Ministro Marco Aurélio. 26 de agosto de 2014.

Diário da Justiça Eletrônico, Brasília. Disponível em: < http://stf.jus.br/portal/diarioJustica/verDiarioProcesso.asp?numDj $=164 \&$ dataPublicacaoDj $=26 / 08 / 2014 \&$ incidente $=3911590 \&$ codCapitulo $=5 \&$ numMateria $=114 \&$ codMateria $=2>$ Acesso em: 09 jul. 2018.

BRASIL. Recurso Extraordinário número 597.854-GO. Universidade Federal de Goiás e Tiago Macedo dos Santos. Relator Ministro Edson Fachin. 28 de abril de 2017. Diário da Justiça Eletrônico, Brasília. Disponível em: < http://redir.stf.jus. br/paginadorpub/paginador.jsp?docTP $=$ TP\&docID $=13642927>$ Acesso em: 09 jul. 2018.

CARVALHO, Cristina Helena Almeida de. Política para o ensino superior no Brasil (1995-2006): Ruptura e continuidade nas relações entre público e privado. In: SILVA JÚNIOR, João dos Reis; OLIVEIRA, João Ferreira de; MANCEBO, Deise (Org.). Reforma universitária: dimensões e perspectivas. Campinas: Alínea, 2006. p. 125139.

CONSELHO NACIONAL DE EDUCAÇÃO. Parecer número CNE/CES 0364 aprovado em 06 nov. 2002. Regularidade da cobrança de taxas em de cursos de pós-graduação, lato sensu, com base no art. 90, da lei 9.394. Brasília: Ministério da Educação, 2002. Disponível em: < http://portal.mec.gov.br/dmdocuments/parecer_cne_0364_sesu.pdf > Acesso em: 09 jan. 2017. 
DEMO, Pedro. Educação na nova Constituição: qualidade e democratização. Em Aberto, Brasília, ano 7, n. 39, jul./set., 1988. Disponível em: < http://emaberto. inep.gov.br/index.php/emaberto/article/view/1711/1682> Acesso em: 04 maio 2018.

DUARTE, Clarice Seixas. A educação como um direito fundamental de natureza social. Educação \& Sociedade, Campinas, v. 28, n. 100 Especial, p. 691-713, out. 2007.

DWORKIN, Ronald Myles. Levando os direitos a sério. 2. ed. São Paulo: Martins Fontes, 2010.

GAVIÃO, Juliana Venturella Nahas. A proibição de proteção deficiente. Revista do Ministério Público do RS, Porto Alegre, n. 61, p. 93-111, maio/out. 2008.

LUCKESI, Cipriano Carlos. Avaliação da aprendizagem escolar: estudos e proposições. 19. ed. São Paulo: Cortez, 2008.

MAXIMILIANO, Carlos. Hermenêutica e aplicação do Direito. 9. ed. Rio de Janeiro: Forense, 1979.

NEVES, Clarissa Eckert Baeta. Ensino Superior no Brasil: expansão, diversificação e inclusão. Trabalho apresentado no XXX Congresso da LASA (Associação de Estudos Latino Americanos). São Francisco, Califórnia, 2012. Disponível em: < http:// flacso.redelivre.org.br/files/2013/03/1114.pdf> Acesso em: 03 maio 2018.

SARLET, Ingo Wolfgang. A eficácia dos direitos fundamentais. $2^{\mathrm{a}}$ ed. Porto Alegre: Livraria do Advogado, 2001.

SARLET, Ingo Wolfgang. Constituição e proporcionalidade: o direito penal e os direitos fundamentais entre a proibição de excesso e de insuficiência. Revista da Ajuris, Porto Alegre, v. 32, n. 98, p. 105-150, jun. 2005.

SILVA, Jorge Pereira da. Interdição de Protecção Insuficiente, proporcionalidade e conteúdo essencial. In: FACULDADE DE DIREITO DA UNIVERSIDADE DE LISBOA. Estudos de Homenagem ao Prof. Doutor Jorge Miranda: Direito Constitucional e Justiça Constitucional. Coimbra: Coimbra, 2012. p. 185-210. Vol. II. 
teoria, história e métodos de trabalho. Belo Horizonte: Fórum, 2013.

STRECK, Lenio Luiz. A dupla face do princípio da proporcionalidade: da proibição de excesso (übermassverbot) à proibição de proteção deficiente (untermassverbot) ou de como não há blindagem contra normas penais inconstitucionais. Revista da Ajuris, Porto Alegre, v. 32, n. 97, p. 172-201, mar. 2005.

Recebido em: 16/07/2018

Aceito em: 28/09/2018 